\title{
TACTILE DIKAITKAN DENGAN PEMBELIAN PRODUK (STUDI KASUS WALLPAPER DINDING)
}

\author{
Ivo Ramadhani \\ Program Studi Desain Interior Fakultas Seni dan Desain \\ Universitas Potensi Utama \\ Email:ivor205@gmail.com
}

\begin{abstract}
ABSTRAK
Karya dari suatau desain interior menjadikan ragam karya agar dapat diterapkan dirumah yaitu desain yang memberikan fasilitas untuk kegiatan hidup hari-hari manusia. Dalam perancangan desian interior manusia menjadi peran penting dalam hal pemikiran desain dan dalam pembuatannya. Membuat desain interior memerlukan tahapan dan prinsip yang berorientasi pada wujud dan ukuran manusia seperti, keadaan jasmani, cara bergerak, bersikap dan tuntutan selera manusia. Dalam hal penelitian ini permasalahan yang akan diangkat adalah tentang studi kasus wallpaper dinding. Metode penelitian yang digunakan adalah deskriptif kuantitatif. Wallpaper dinding dalam pangsa pasar penjualan, merupakan salah satu produk yang banyak diminati untuk mengisi kebutuhan ruang perkantoran dan rumah disampimg memfungsikan karya seni yang dituangkan dalam sebuah dinding agar terlihat artistik. Berbagai macam desain wallpaper disuguhkan oleh penjual untuk menarik minat konsumen dan merebut pangsa pasar. Adapun jenisjenis bahan yang digunakan wallpaper dinding adalah kain, heavy duty paper, vinyl, kertas, serat alami foil dan beludru bahan-bahan tersebut memilik tekstur yang berbeda dimasing-masing lapisan. Tekstur yang ditimbulkan dari berbagai macam bahan tersebut, akan menghubungkan indra peraba manusia dengan produk. Tactile atau segala sesuatu yang berkaitan dengan indra peraba atau sentuh, dapat dirasakan oleh semua permukaan tubuh manusia. Interaksi yang ditimbulkan antara manusia dengan produk bahan akan memunculkan pendapat terhadap produk tersebut. Pendapat yang muncul seketika akan memberikan penilaian khusus ketika konsumen memilih bahan material (studi kasus wallpaper dinding) sesuai dengan kebutuhan mereka. Pendapat tersebut akan menciptakan sebuah standar sebuah kenyamanan yang muncul dari indra peraba/sentuh. Pada akhirnya penelitian akan memperlihatkan pengaruh karakter material terhadap pilihan konsumen terhadap produk wallpaper.
\end{abstract}

Kata kunci: desain, wallpaper, bahan, tactile

\begin{abstract}
The work of an interior design makes the variety of works that can be applied at home, namely design that provides facilities for living activities of human days. In the design of the interior desian, human becomes an important role in terms of design thinking and in its making. Making interior designs requires stages and principles that are oriented towards human form and size such as, physical state, how to move, behave and the demands of human tastes. In terms of this research the problem to be raised is about case studies of wall wallpaper. The research method used is quantitative descriptive. Wall wallpaper in the market share of sales, is one of the products that are in great demand to fill the needs of office space and houses to enable the work of art that is poured into a wall to make it look artistic. Various types of wallpaper designs are presented by sellers to attract consumer interest and capture market share. The types of materials used for wall paper are cloth, heavy duty paper, vinyl, paper, natural foil and velvet materials that have different textures
\end{abstract}


in each layer. The texture generated from various types of material, will connect the sense of human touch with the product. Tactile or anything related to the sense of touch or touch can be felt by all surfaces of the human body. The interactions that occur between humans and material products will give rise to opinions on these products. Opinions that appear immediately will provide a special assessment when consumers choose material (wall paper case studies) according to their needs. This opinion will create a standard of comfort that arises from the sense of touch. In the end the research will show the influence of material characteristics on consumer choice on wallpaper products.

Keywords: desain, wallpaper, bahan, tactile

\section{PENDAHULUAN}

Wallpaper dinding pertama kali digunakan oleh bangsa cina kuno yakni sekitar pada abad 200 SM, pada masa itu bangsa cina menemukan kertas dan kertas tersebut digunakan mereka untuk menutupi dinding dirumah mereka dengan cara menempelkan kertas lalu mereka menghiasi kertas tersebut dengan panel beras dan mengambar simbol-simbol agama, lanskap dan beberapa binatang. Pada abad pertengahan di eropa, orang-orang eropa mengunakan tenunan permadi yang untuk menutupi dinding agar mengurangi rasa dingin, kelembapan dan sebagai alat untuk memperhias ruangan agar tidak terkesan suram. Christophe-Philippe Oberkampf, adalah yang membuat mesin cetak wallpaper untuk pertama kali di tahun 1785 adalah orang berkebangsaan perancis yang pada saat ini membuat wallpaper dinding dengan alasan untuk pengganti material cat yang mahal.

Mayoritas konsumen masih menjatuhkan pilihan kepada cat sebagai pewarna untuk dinding interior, namun bagi beberapa konsumen lainya cat tembok dinilai bersifat monoton dikarenakan hanya mengunakan satu warna saja sehingga banyak juga dari kalangan masyarakat memilih beralih pada pelapis dinding yang mampu menciptakan nuansa keindahan dengan motif, warna dan ragam gambar yang dinilai dapat menghasilkan suasana yang lebih nyata. Wallpaper sendiri berarti kertas dinding, dengan kata lain adalah pelapis tembok dengan motif indah. Desain dan motif merupakan hal utama untuk keberhasilan sebuah produk agar dapat dinikmati oleh masyarakat. Cara menentukan keberhasilan itu dapat dilihat dari besar kecilnya minat pasar terhadap produk yang dijual. Aktifitas desain menjadi suatu kegiatan untuk melahirkan suatu gagasan yang memiliki nilai futuristik dan dapat melihat keinginan pasar dan tren yang ada pada saat itu. Ketika seorang desainer menciptakan suatu produk, sudah seharusnya desainer tersebut dapat membaca situasi pasar dan melihat kebutuhan pasar. Desain interior termasuk kategori desain yang memiliki fungsional, yakni desain yang memberikan arti untuk kegiatan sehari-hari manusia. Dalam perancanganya, manusia merupakan faktor penting dan aspek utama. Membuat desain interior memerlukan tahapan dan prinsip yang berorientasi pada anatomi dan ukuran manusia seperti, keadaan jasmani, cara bergerak, bersikap dan tuntutan selera manusia. Memerlukan pemikiran yang konseptual baik dari sisi fungsi maupun estetis agar desain sesuai dengan permintaan konsumen. Keindahan interior merupakan salah satu pemenuh hasrat bagi setiap manusia dalam sebuah ruangan. keindahan mencakup fasilitas dinding, 
fasilitas simpan, fasilitas kerja dan fasilitas tidur. Dalam penelitian ini studi kasus yang diambil adalah fasilitas dinding.

Dengan perkembangan teknologi yang pesat, fasilitas dinding mengalami kemajuan dari sisi desainnya. Fasilitas dinding yang indah bila dipandang umumnya dirancang dengan mempertimbangkan sisi ergonomi (kenyamanan). Wallpaper dinding, jam dinding, hiasan dinding merupakan beberapa contoh dari produk fasilitas dinding. Dalam penelitian ini, produk fasilitas dinding yang dijadikan studi kasus adalah wallpaper dinding. Wallpaper dinding merupakan bagian dari fasilitas dinding yang memiliki motif ragam corak serta memiliki berbagai macam materil yang bagus, kemudian berlapiskan cat khusus atau motif yang timbul sesuai dengan motif corak. Wallpaper dalam situasi pasar furniture, merupakan salah satu produk yang banyak diminati untuk mengisi kebutuhan ruang perumahan maupun kantor disamping tidak mengunakan cat tembok biasa, wallpaper dapat dibuat sesuai dengan corak atau gambar yang diinginkan. Berbagai macam desain wallpaper disuguhkan oleh distributor furniture untuk dapat memenuhi kebutuhan pasar. Penelitian ini mengambil segmentasi pasar kelas menengah ke bawah.

Komponen wallpaper dinding terdiri dari kertas sebagai bahan utama, lapisan dalam terdiri dari lem untuk merekatkan kedinding dan bagian luar dari wallpaper adalah gambar atau motif wallpaper. Keindahan dari sebuah wallpaper selain dari motif desain juga dapat terlihat secara visual melalui kain pelapisnya. Bahan untuk wallpaper biasanya menggunakan material kertas, heavy duty paper, vinyl, kain, serat alami, foil dan beludru. Gambar yang ditimbulkan memiliki tekstur motif embos yang dapat dirasa oleh indra peraba sesuai dengan gambar dan motif yang muncul. Untuk material kertas material yang didapatkan adalah terbuat dari kertas biasa, sehingga jenis ini mudah sobek. Jika bahan heavy duty memiliki sifat bahan yang kuat dan biasanya motif pada bahan ini sering diberi motif timbul (embos). Bahan vinyl bahan ini tahan lembab dibanding produk wallpaper bahan kertas. Bahan kain biasanya berbahan kain sutra, tenun linen berbahan kain ini memiliki beraneka motif tekstur warna yang beragam. Sedangkan material beludru memiliki bahan yang sangat elegan dan terkesan modern. Tekstur yang dimunculkan oleh beberapa material tersebut, akan menghubungkan indra peraba manusia dengan produk. Tactile atau segala sesuatu yang berkaitan dengan indra peraba atau sentuh, dapat dirasakan oleh semua permukaan tubuh manusia. Interaksi yang terjadi antara manusia dengan produk akan memunculkan persepsi terhadap produk tersebut. Persepsi yang muncul dari sensasi tactile tersebut akan memberikan penilaian khusus ketika konsumen memilih wallpaper (studi kasus wallpaper dinding) untuk kebutuhan mereka. Persepsi tersebut nantinya akan menjadi sebuah standar kenyamanan yang muncul dari indra peraba atau sentuh.

Pemilihan gambar yang menarik akan menjawab semua kebutuhan yang merupakan salah satu cara menciptakan sebuah desain yang baik. Pembuatan desain tidak hanya berasal dari tampilan visual (panca indra penglihatan) yang indah, tetapi juga bisa melibatkan kepuasan dari panca indra yang lain. Munculnya istilah multi sensory design merupakan jawaban dari pemenuhan kebutuhan desain yang bisa memuaskan kebutuhan pemakai lebih dari sekedar tampilan visual. 
Menurut Dharmawan (2012), Multi Sensory Design merupakan suatu pendekatan pemecahan masalah perencanaan dan perancangan desain interior dengan memanfaatkan semua potensi indera manusia, dengan tujuan agar pesan yang ingin disampaikan tercapai. Cakupan dari multi sensory design adalah: penglihatan (vision), penciuman (smell), pendengaran (hearing), perasa (taste), dan peraba/ sentuhan (touch/tactile).

\section{STUDI LITERATUR}

Studi literatur dalam penulisan ini yakni pencarian refrensi teori-teori yang berkaitan dengan permasalahn yang ditemukan. Teknik studi literatur tersebut berfungsi untuk mendapatkan landasan teori dan informasi yang dibutuhkan oleh peneliti. Adapun studi literatur dalam acuan penulisan makalah ini adalah sebagai berikut:

\section{Material dan Tactile}

Pemahaman tentang material merupakan suatu bagian penting bagi seorang desainer wallpaper. Material merupakan salah satu tolak ukur yang tidak boleh dianggap sepele dalam membuat motif dan gambar. Dalam perancangan fasilitas dinding, material bahan yang bagus merupakan salah satu daya tarik pembeli untuk memilih produk wallpaper. Agar menjadi penarik minat konsumen dalam memilih bahan wallpaper adalah dengan melihat material yang memiliki berbagai macam klasifikasi tekstur, pattern, softness, dan warna. Material yang dipakai untuk bahan bahan wallpaper ini adalah diantaranya adalah kertas kertas, heavy duty paper, kain, viny, foil dan beludru

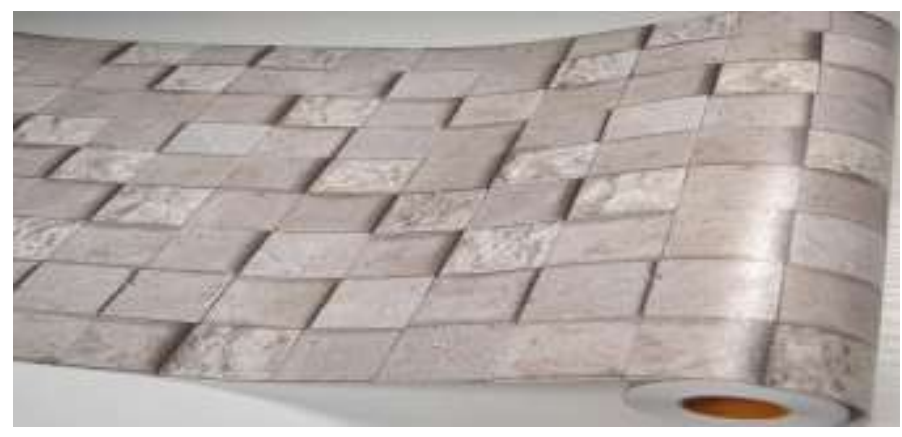

Gambar 1. Wallpaper berbahan kertas (kain) (sumber: www.wallpaperdinding.com, 2016) 


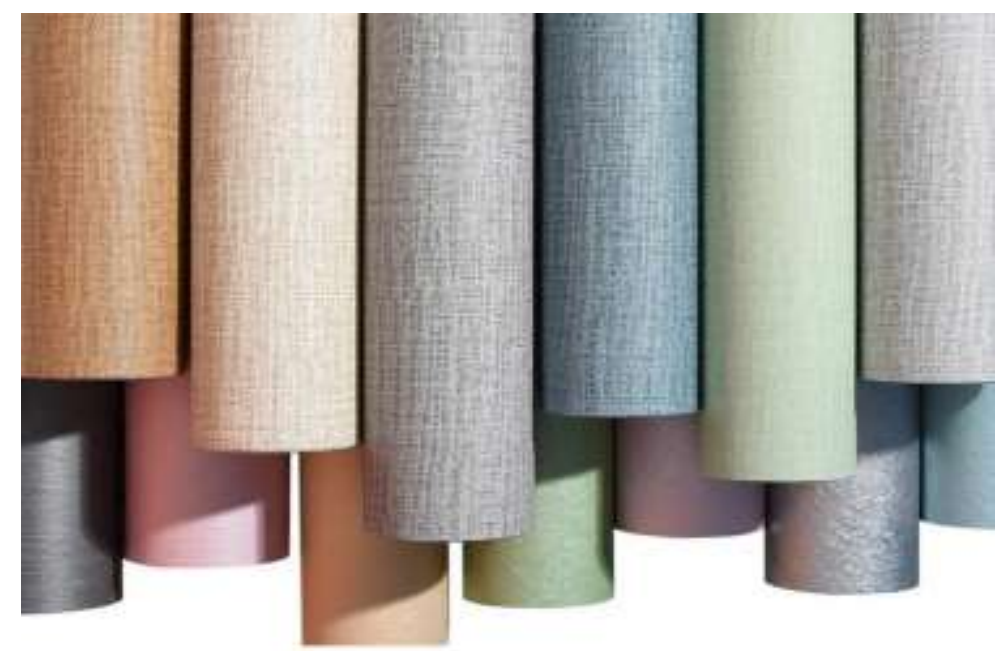

Gambar 2. Contoh wallpaer bahan heavy duty paper (sumber: www.wallpaperdinding.com,2016)

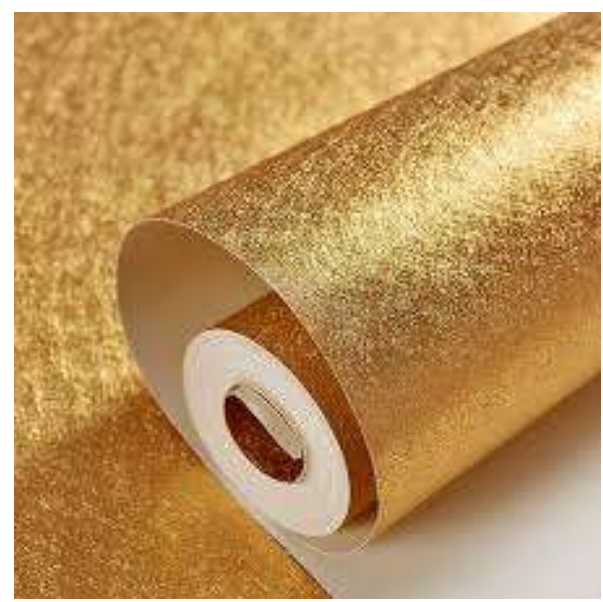

Gambar 3. contoh wallpaper bahan foil (sumber: www.wallpaperdinding.com,2016)

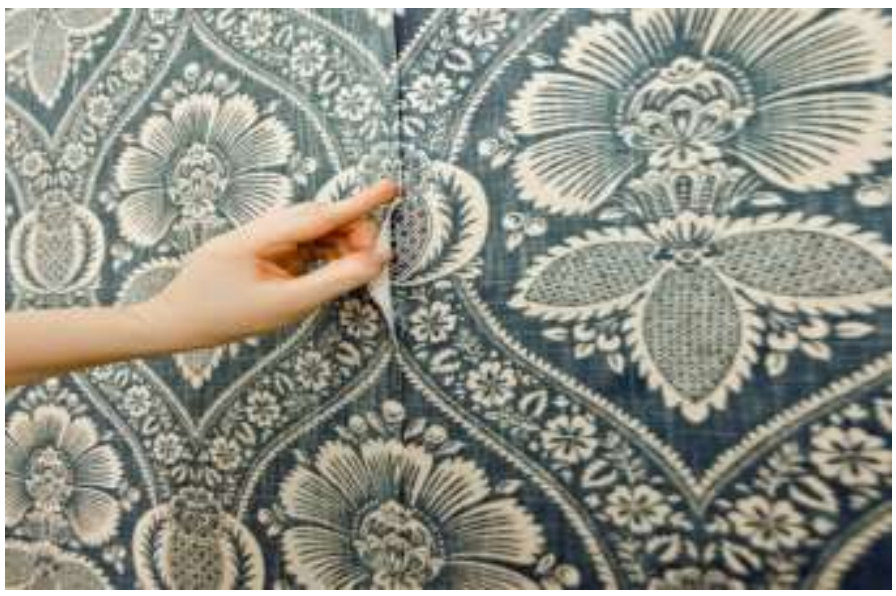

Gambar 4. contoh bahan wallpaper beludru (sumber : www.wallpaperdinding.com,2016)

Tactile (taktil) secara etimologis dapat diartikan sebagai segala sesuatu yang berkaitan dengan rabaan atau sentuhan. Proses terjadinya tactile dimulai dari adanya stimulus dari luar 
badan manusia. Stimulus tersebut akan disampaikan oleh saraf-saraf sensori tubuh dan akan ditanggapi oleh otak. Heryati E (2002) menmbagikan sensor motorik tubuh di bagi atas 2 sistem yakni:

1. Sistem eksteroseptik, kesadaran akan informasi dari luar tubuh yang didapat melalui panca indera kulit.

2. Sistem proprioseptik Kedua sistem tersebut akan berpengaruh terhadap persepsi yang sampai ke tubuh manusia, diantaranya persepsi taktual (tactile).

\section{Pengertian interior}

Pada proses pemilihan desain dari suatu ruangan adalah hal yang cukup rumit, dikarenakan bahwa baik dari pemilihan warna, furniture dan lain-lainya harus lah sesuai dengan apa yang indah dipadang mata. Interior berperan aktif untuk menghidupkan aura dari suatu ruangan dan didukung dengan furniture yang ada didalamnya. Interior sendiri mempunyai arti yatiu suatu ilmu pengetahuan yang memahami mengenai sebuah karya seni yang ada pada suatu bangunan ruang dalam. Desain interior merupakan salah satu bidang keilmuan yang didasarkan pada ilmu desain, bidang keilmuan tersebut berguna unruk menciptakan suatu lingkungan binaan (ruang dalam) bersama elemen pendukung lainnya, baik dalam bentuk fisik maupun nonfisik. Dalam pekerjaannya desain interior terbagi atas 3 kelompok, yakni:

1. Perancangan interior tetap yakni perancangan desain interior yang diawali dengan perancangan denah, animasi, market dan lain-lain.

2. Perancangan interior bergerak, yakni perancangan desain interior yang bersifat makro misalkan pembuatan desain furniture, desain produk dan handyvraft.

3. Perancangan dekoratif yakni perancangan yang bersifat menghias seperti menghias ruangan pernikahan dan mendesain ruangan untuk satu acara.

Dalam menata interior dibutuhkan pemahaman yang berkaitan dengan aspek kebutuhan manusia sebagai makhluk individual maupun sosial didalam suatu ruang. Berikut pengetahuan yang wajib diketahui oleh seorang penata interior yaitu:

a. Mengetahui sejarah desain interior

b. Memahami psikologi dalam desain Interior

c. Memahami sosiologi dalam desai interior

d. Mengetahui makna penting ergonomi

e. Menguasai konstruksi bangunan desain interior

f. Memahami fisika teknik desain interior dan

g. Mengetahui metodologi dan estetika.

Selain itu seorang desain interior juga dituntut untuk memahami dan menguasai keterampilan pada proses perancangan yang diantaranya yaitu kemahiran dalam pembuatan program, kemahiran menciptakan presentasi desain, dan kemampuan komunikasi serta masih banyak lagi diantara lainnya. Adapun tujuan dari perancangan suatu design interior adalah:

1. Untuk membuat ruangan agar lebih fungsional dan indah, disamping itu agar membuat setiap orang akan nyaman ketika berada didalam ruangan. 
2. Interior merupakan sesuatu yang berada di dalam bangunan. Bisa juga diartikan seperti desain atau dekorasi di dalam struktur.

3. Interior dapat memadukan antara warna, furniture dan lainnya

4. Harus memiliki kreatifitas artinya dalam mendesain interior seorang designer interior harus lah memilik kemampuan agar interior dinilai beda dari pada yang lain dan tidak monoton.

Pada proses perancangannya menggunakan model berfikir yang melibatkan suatu proses dengan sifat tidak statis dan memerlukan pemikiran kritis serta kreatif upaya menggabungkan daya cipta, perkembangan teknologi maupun unsur estetika yang memenuhi syarat untuk diproduksi. Sekalipun desain itu adalah disiplin keilmuan yang menyangkut sains alam (hal-hal yang fisis) dan sains sosial yang menyangkut peilaku (behaviour), peranan seni dalam pengertian cita rasa estetis juga memegang peranan dalam pemecahan masalah dan pengambilan keputusan (Buchori, 2000: 123).

Proses perancangan tata ruang, manusia merupakan tokoh utama yang berperan menempati ruang, oleh sebab itu harus diberikan perhatian khusus dengan segala sesuatu yang berkenaan dengan masalah-masalah behaviour. Manusia merupakan kesatuan materi dan non materi dari berbagai unsur yang tidak dapat dipisah-pisahkan,

- manusia itu sesungguhnya materi yang berohani, yang memanusiakan manusia adalah materi kerohaniannya.

- manusia sebagai materi adalah berupa benda alam yaitu salah satu makhluk di alam ini yang disebut makhluk biologis.

- sebagai non materi yaitu manusia mempunyai unsur yang disebut jiwa atau roh, biasa disebut sebagai makhluk psikis.

- manusia merupakan anggota dari suatu kelompok masyarakat, manusia menyadari tanpa hubungan dengan manusia lain adalah tidak lengkap.

- hakekat manusia adalah berada dalam suatu kebersamaan.

- Personal safety: manusia memerlukan keamanan bagi dirinya.

- Teritoriality: menunjukkan adanya suatu wilayah yang dikuasai.

- Personal Space: menunjukkan adanya kebutuhan yang bersifat lebih pribadi.

- Personal Statu: keinginan manusia untuk menunjukkan status sosial yang berbeda

Dengan memperhatikan faktor-faktor tersebut maka tidak dipungkiri bahwa manusia merupakan makhluk biologis, psikis dan sosial. Manusia akan melewatkan sebagian hidupnya di dalam ruang dan mengatur diri mereka sendiri secara naluriah di dalam ruang tersebut. Didalam mendesain interior digunakan beberapa konsep interior dalam penataan suatu interior yakni:

1. Rustik

Rustik dapat diartikan sebagai sesuatu yang sederhana dan terkesan kuno. Rustik memiliki konsep yang bertemakan lingkungan dan biasanya alam menjadi tolak ukur konsep rustik. 


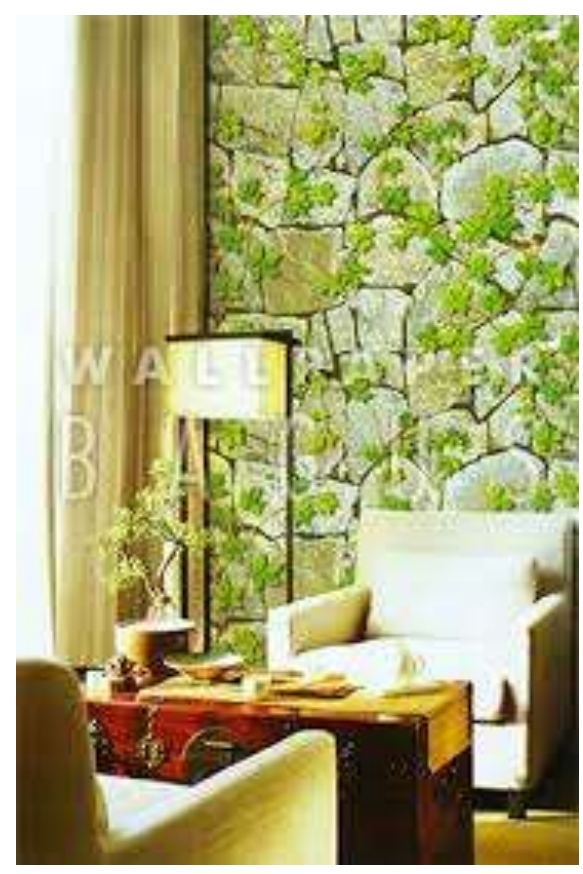

Gambar 5. Penerapan wallpaper dinding bertema rustik (sumber: wallpaperbagus.co.id)

2. Klasik

Klasik yakni konsep yang menitik beratkan harmonisasi dan keseimbangan guna menghasilkan citra yang bagus dengan memperhitungkan nilai-nilai filosofi desain interior yang sering digunakan pada zaman dahulu.

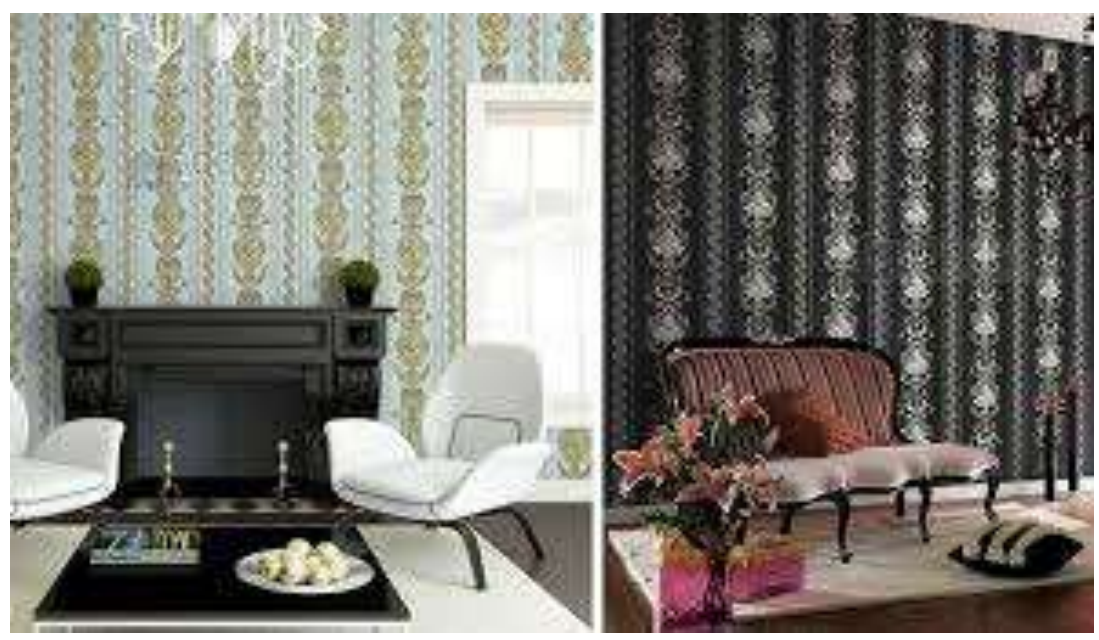

Gambar 6. Penerapan wallpaper dinding bertema klasik (sumber: wallpaperbagus.co.id)

3. Modern minimalis

Konsep modern minimalis lebih sering diterapkan guna menciptakan kesan citra terbaik melaui filosofi arsitektur terkemuka. Banyak diantara masyarakat masih beranggapan bahwa konsep minimalis hanya suatu desain yang mampu menghasilkan ruang sederhana tetapi tetap berkeinginan memiliki nilai estetika dan ruang yang lebih besar serta 
luas. Melainkan konsep modern minimalis merupakan konsep ruang yang tidak adanya pemborosan terhadap penggunaan bahan yang tidak ramah terhadap alam.

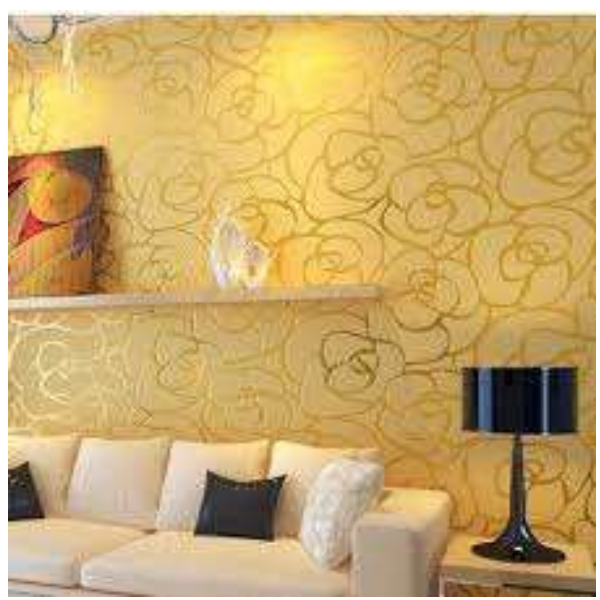

Gambar 7. Penerapan wallpaper dinding bertema modern minimalis (sumber: wallpaperbagus.co.id)

\section{PEMBAHASAN}

\section{Material Bahan Wallpaper}

Penelitian ini mengambil contoh dari beberapa bahan diantaranya seperti pada penjelasan tabel berikut:

Tabel 1. Keterangan Bahan Material Wallpaper

\begin{tabular}{|l|l|l|}
\hline No & \multicolumn{1}{|c|}{$\begin{array}{c}\text { Bahan Material } \\
\text { Wallpaper }\end{array}$} & \multicolumn{1}{|c|}{ Keterangan } \\
\hline 1. & Kertas & $\begin{array}{l}\text { Tidak dengan campuran material bahan lainnya, motif dan } \\
\text { corak wallpaper pada bahan kertas lebih memiliki } \\
\text { keberagam dari jenis wallpaper lainnya akan tetapi bahan } \\
\text { kertas memiliki kekurangan yaitu mudah sobek. }\end{array}$ \\
\hline 2. & Heavy Duty & $\begin{array}{l}\text { Merupakan bahan wallpaper yang dapat dibersihkan, } \\
\text { bersifat kuat atau tebal sehinnga tidak mudah berkerut dan } \\
\text { memiliki motif timbul dengan lapisan linen. }\end{array}$ \\
\hline 3. & Kain wallpaper & $\begin{array}{l}\text { Wallpaper berbahan kain cenderung lebih mudah kusut dan } \\
\text { proses pemasangan dan perawatan wallpaper berbahan kain } \\
\text { butuh cara khusus. }\end{array}$ \\
\hline 4. & Vinyl & $\begin{array}{l}\text { Bahan yang tidak mudah sobek, tidak mudah kotor dan } \\
\text { tahan terhadap lembab. }\end{array}$ \\
\hline 5. & Foil Wallpaper & $\begin{array}{l}\text { Bahan foil dapat menciptakan efek mengkilap akan tetapi } \\
\text { wallpaper ini terbilang bersifat tipis dan jenis bahan Foil } \\
\text { cukup jarang ditemui. }\end{array}$ \\
\hline
\end{tabular}




\begin{tabular}{|l|l|l|}
\hline 6. & Beludru Wallpaper & $\begin{array}{l}\text { Bahan Beludr terbuat dari serat wol yang dipadu dengan } \\
\text { bahan kertas ataupun kain. Wallpaper beludru lebih } \\
\text { dianjurkan pada pemakaian pada dekorasi klasik. }\end{array}$ \\
\hline
\end{tabular}

\section{Lokasi Penelitian}

Lokasi penelitian untuk melihat pemilihan wallpaper oleh konsumen yaitu pada toko wallpaper Medan.Wallpaper Medan merupakan salah satu pusat perdagangan interior wallpaper Medan menyediakan berbagai koleksi berkualitas untuk hunian, kantor, aksesoris, sampai ruang komersial dan menyediakan lebih produk-produk berkualitas dengan suasana belanja yang menyenangkan.

Berikut beberapa contoh produk (wallpaper interior) yang dijual di wallpaper Medan :

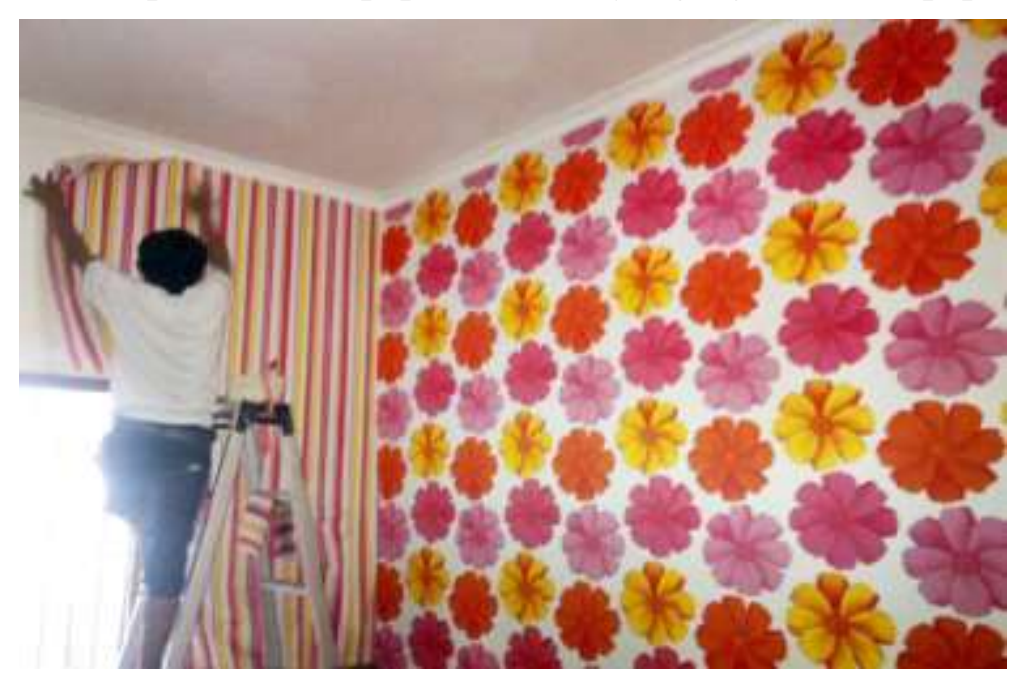

Gambar 8. Proses pemasangan wallpaper (Sumber : wallpaper Medan, 2016)

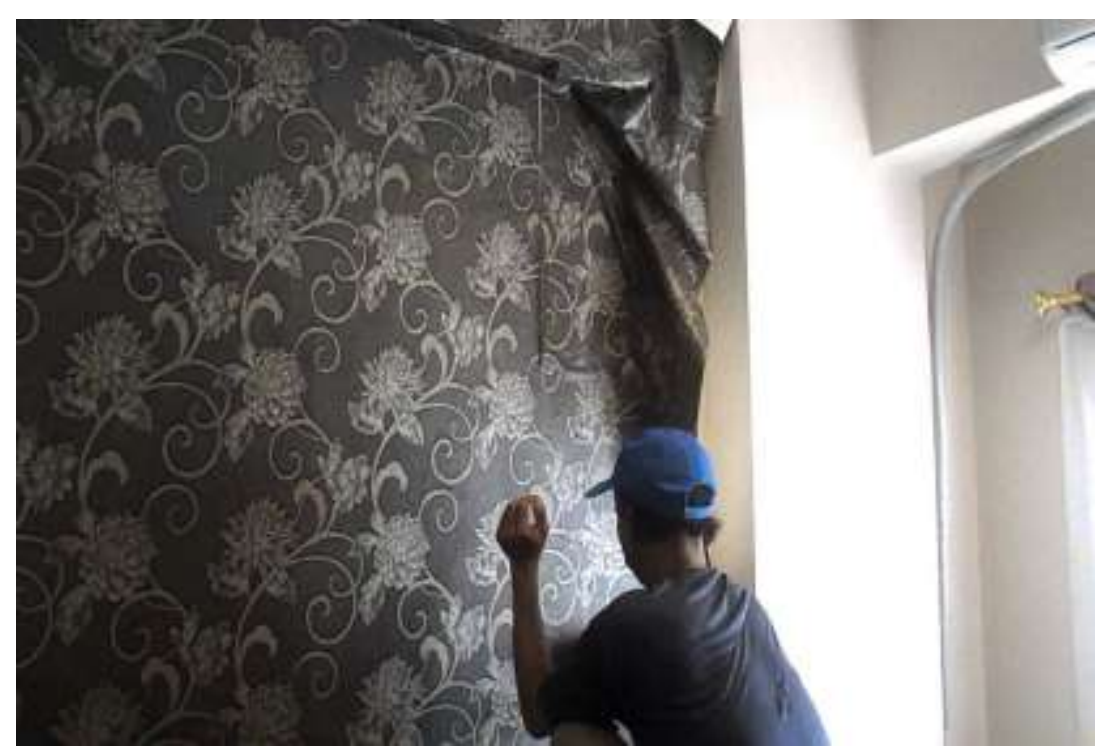

Gambar 9. Proses pemasangan wallpaper (Sumber : wallpaper Medan, 2016) 


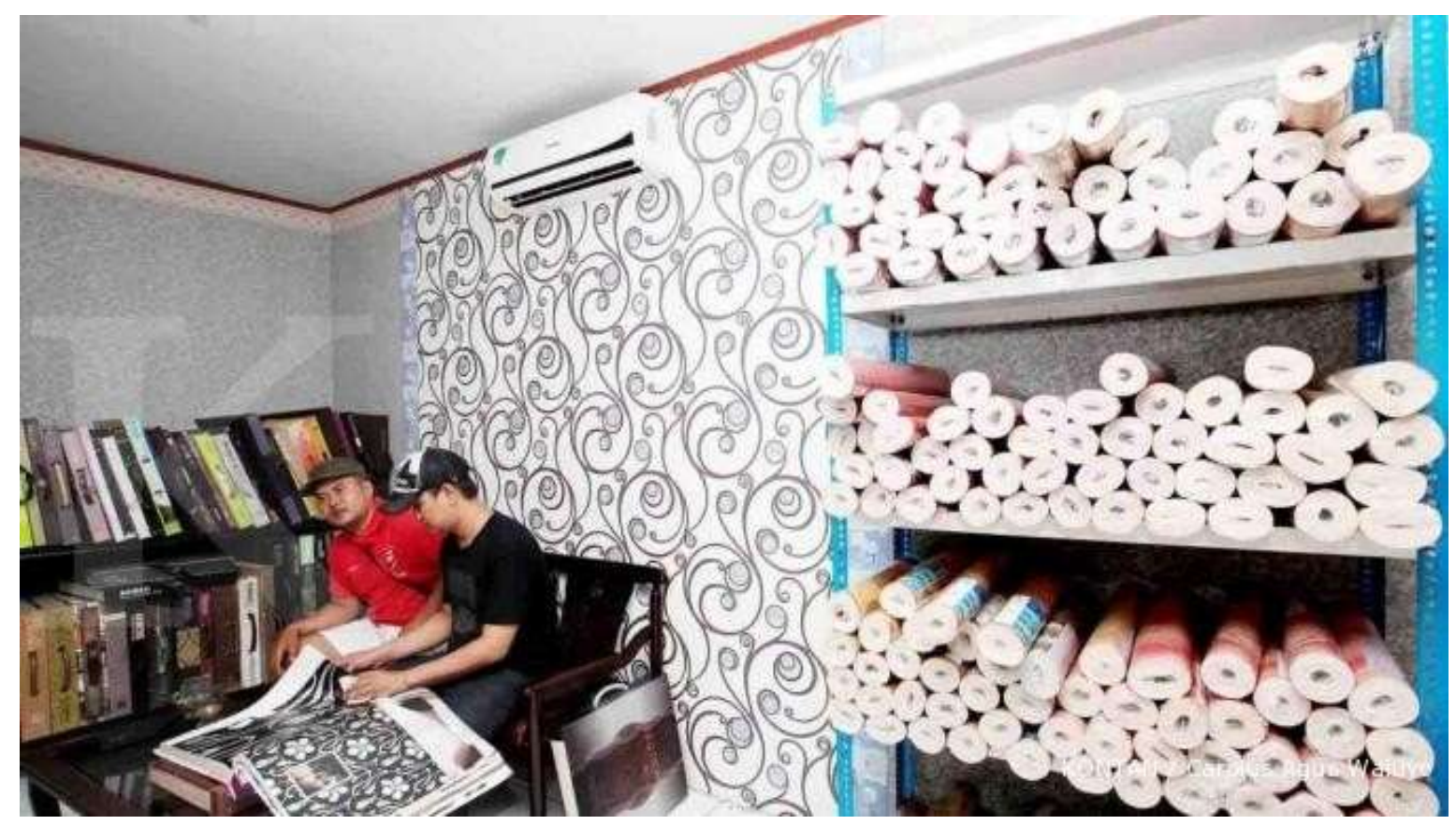

Gambar 10. Produk wallpaper medan

(Sumber : wallpaper Medan, 2016)

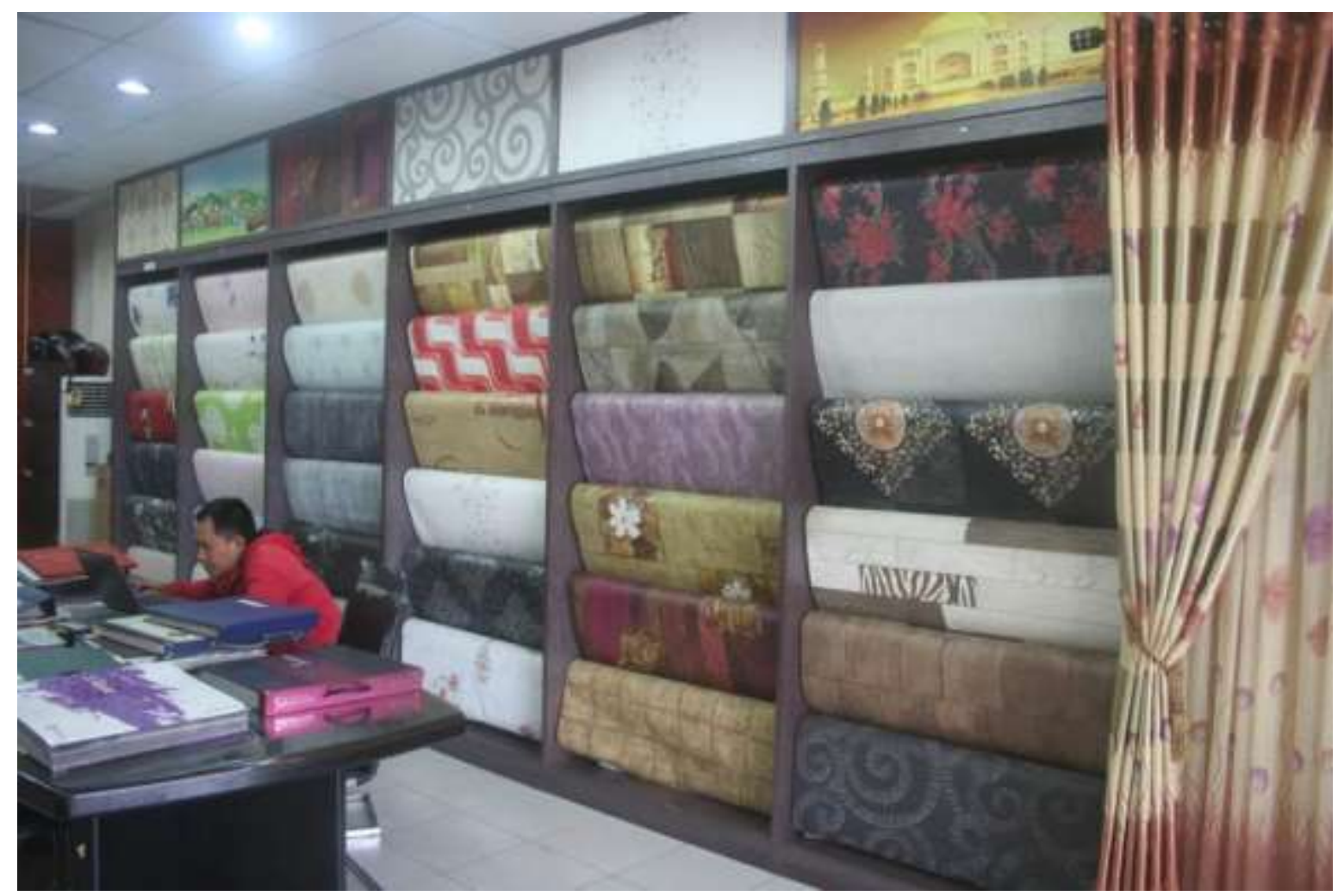

Gambar 11. Produk wallpaper medan (Sumber : wallpaper Medan, 2016) 


\section{Analisa}

Metode dalam penelitian ini yaitu menggunakan metode deskriptif kuantitatif sehingga keabsahan data diperoleh melalui validitas dan reliabilitas. Berikut hasil analisa berdasarkan metode deskriptif kuantitatif dapat dijabarkan sebagai berikut:

1. Kecendrungan pemilihan material wallpaper berdasarkan kesan raba/ tactile. Tekstur material bahan wallpaper diantaranya yaitu Kertas, Heavy Duty, Kain wallpaper, Vinyl, Foil Wallpaper, dan Beludru Wallpaper. Material yang banyak diminati berdasarkan kesan raba dapat dilihat dari tabel berikut :

Tabel 2. Tingkat Pemilihan Bahan Material Wallpaper

\begin{tabular}{|l|l|c|}
\hline No & \multicolumn{1}{|c|}{$\begin{array}{c}\text { Bahan Material } \\
\text { Wallpaper }\end{array}$} & $\begin{array}{c}\text { Tingkat pemilihan Bahan } \\
\text { Material Wallpaper }\end{array}$ \\
\hline 1. & Kertas & $25,5 \%$ \\
\hline 2. & Heavy Duty & $60,10 \%$ \\
\hline 3. & Kain wallpaper & $35, \%$ \\
\hline 4. & Vinyl & $75 \%$ \\
\hline 5. & Foil Wallpaper & $20,75 \%$ \\
\hline 6. & Beludru Wallpaper & $50 \%$ \\
\hline
\end{tabular}

2. Kecendrungan pemilihan berdasarkan harga material dari bahan wallpaper (dari pihak pengrajin/ produsen).

Tabel 3. Tingkat Pemilihan Berdasarkan Harga

\begin{tabular}{|l|l|c|}
\hline No & \multicolumn{1}{|c|}{$\begin{array}{c}\text { Bahan Material } \\
\text { Wallpaper }\end{array}$} & $\begin{array}{c}\text { Tingkat pemilihan berdasarkan } \\
\text { harga Bahan Material Wallpaper }\end{array}$ \\
\hline 1. & Kertas & $70,5 \%$ \\
\hline 2. & Heavy Duty & $40 \%$ \\
\hline 3. & Kain wallpaper & $10,75 \%$ \\
\hline 4. & Vinyl & $30,25 \%$ \\
\hline 5. & Foil Wallpaper & $20,75 \%$ \\
\hline 6. & Beludru Wallpaper & $15,20 \%$ \\
\hline
\end{tabular}

\section{KESIMPULAN}

Keberhasilan sebuah desain terletak pada mampu tidaknya seorang desainer menjawab kebutuhan user atau pengguna. Peran dari wallpaper dapat mengantikan peran dari cat tembok biasa. Fungsi dan menyentuh aspek sensory lain merupakan penunjang sebuah produk dibeli oleh konsumen. Estetis dapat dicapai melalui indra penglihatan yang memberikan kepuasan visual. Pasar sepenuhnya akan membaca kebutuhan dari konsumen dan memenuhi kebutuhan tersebut dengan target produk dapat terjual. Hasil penelitian menunjukkan bahwa tekstur material embos dari motuf gambar mempengaruhi persepsi manusia terhadap kenyamanan. Tetapi hal ini bisa tidak menjadi patokan utama untuk menarik konsumen membeli produk wallpaper tersebut disamping dari harga yang bersaing. 
Ada faktor lain selain kenyamanan yang ditimbulkan oleh material, yaitu faktor efesiensi dan ekonomis. Konsumen akan memilih material yang mudah dalam segi perawatan dan murah dari segi harga.

\section{DAFTAR PUSTAKA}

[1] Heriyati, E. Persepsi Kinestetik dan Persepsi Taktual. Bahan Ajar. 2010

[2] International Building Products Data Catalogue 92/93, A division of Wilmington Publiching Ltd., 1992.

[3] Lucky, S. 1988. Diktat Teknologi Bahan. Bandung: Penerbit ITB

[4] Pile, John f. 1995. Interior Design 2ndedition.New York: Harry N. Abrams.Inc

[5] Robson, Colin. 1993. Real World Research. Oxford, UK: Blackwell Publishers

[6] Salkind, Neil J. 1997. Exploring Research: Third Edition. NJ: Prentice Hall Inc

[7] Sugiyono. 2010. Metode Penelitian Kuantitatif, Kualitatif dan R\&D. Alfabeta. Bandung.

[8] Syarief, A. 2010. Materi Kuliah Metode Penelitian Desain. ITB

\section{Web Site}

[9] Dwi yani interior. 2011. http://dwiyani interior.blogspot.com/2013/03/penjelasan-ataupengertian-interior.html (diakses Februari 2016)

[10] http://wallpaperbagus.co.id/cgi-sys/suspendedpage.cgi(diakses Februari 2016)

[11] Arsitektur Interior. https://endrakrn.wordpress.com (diakses Februari 2016) 